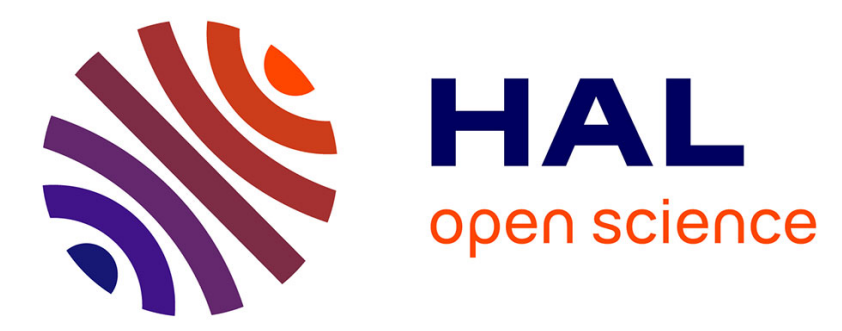

\title{
Gastrointestinal safety of triflusal solution in healthy volunteers: a proof of concept endoscopic study
}

Rosa M. Antonijoan, Ignasi Gich, Analia Azaro, Sergio Sainz, Joaquim

Balanzó, Iñaki Izquierdo, Javier Borja, Esther Donado, Iris Blanch, Manel J.

Barbanoj

\section{To cite this version:}

Rosa M. Antonijoan, Ignasi Gich, Analia Azaro, Sergio Sainz, Joaquim Balanzó, et al.. Gastrointestinal safety of triflusal solution in healthy volunteers: a proof of concept endoscopic study. European Journal of Clinical Pharmacology, 2011, 67 (7), pp.663-669. 10.1007/s00228-011-1004-9 . hal-00670759

\section{HAL Id: hal-00670759 \\ https://hal.science/hal-00670759}

Submitted on 16 Feb 2012

HAL is a multi-disciplinary open access archive for the deposit and dissemination of scientific research documents, whether they are published or not. The documents may come from teaching and research institutions in France or abroad, or from public or private research centers.
L'archive ouverte pluridisciplinaire HAL, est destinée au dépôt et à la diffusion de documents scientifiques de niveau recherche, publiés ou non, émanant des établissements d'enseignement et de recherche français ou étrangers, des laboratoires publics ou privés. 
Gastrointestinal safety of triflusal solution in healthy volunteers:

A proof of concept endoscopic study

Rosa M. Antonijoan ${ }^{1}$, Ignasi Gich ${ }^{1}$, Analia Azaro ${ }^{1}$, Sergio Sainz ${ }^{2}$, Joaquim Balanzó ${ }^{2}$, Iñaki Izquierdo ${ }^{3}$, Javier Borja ${ }^{3}$, Esther Donado ${ }^{3}$, Iris Blanch ${ }^{3}$, Manel J. Barbanoj ${ }^{1}$.

1. Clinical Pharmacology Department, Hospital de la Santa Creu I Sant Pau. Barcelona. Spain.

2. Gastroenterology Department. Hospital de la Santa Creu i Sant Pau. Barcelona. Spain.

3.Clinical Development Unit. J. Uriach y Compañía, S.A. Palau-solità i Plegamans. Barcelona. Spain.

EudraCT Number: 2006-007033-12

\section{Corresponding autor:}

J.Borja

J. Uriach y Compañía, S.A.

Avgda. Camí Reial, 51-57

08184 Palau-solità i Plegamans

Barcelona

Spain

Phone 34938630306

e-mail: javier.borja@uriach.com

\section{Abstract}

Pourpose: Triflusal is an antiplatelet agent that irreversibly acetylates cyclooxygenase isoform $1(\mathrm{COX}-1)$ and therefore inhibits thromboxane biosynthesis. Triflusal was initially 
marketed as capsules containing $300 \mathrm{mg}$ of active substance. In 2006 a new oral $600 \mathrm{mg}$ (10 $\mathrm{ml}$ ) oral solution form of triflusal was authorized in Spain. The primary aim of this study was to compare the gastrointestinal safety of triflusal oral solution with triflusal capsules in healthy volunteers.

Methods: Sixty healthy subjects were randomly assigned, in a $2.5: 2.5: 1$ ratio, into three groups with 25 subjects receiving one bottle of triflusal oral solution $(600 \mathrm{mg})$ daily, 25 subjects receiving two triflusal capsules $(600 \mathrm{mg})$ once daily, and 10 subjects receiving two placebo capsules once daily, respectively, during seven consecutive days. Gastroscopy was performed at base line before administration of study drugs and after 4-8 hours of the last dose of study drugs. Effects on esophagus, stomach and duodenum were measured in accordance with a modified Lanza scale.

Results: At baseline no differences between groups were detected. After treatment, median global scores in the placebo, triflusal solution and triflusal capsules groups were, respectively, 0,1 , and 3 ( $p=0.003$ for comparison between placebo and triflusal capsules and $p=0.042$ for comparison between triflusal solution and triflusal capsules). There were no significant differences between triflusal solution and placebo. All treatments were well tolerarted.

Conclusion: In healthy subjects, triflusal solution induced less endoscopically apparent gastrointestinal mucosal damage than triflusal capsules and did not induce more damage than placebo in healthy volunteers.

Key words: Triflusal, antiplatelet agents, gastrointestinal safety, clinical trials. 


\section{Introduction}

Triflusal is an antiplatelet agent marketed in 1981 as capsules containing $300 \mathrm{mg}$ of active substance. Triflusal irreversibly acetylates cyclooxygenase isoform $1(\mathrm{COX}-1)$ and therefore inhibits thromboxane biosyntesis [1,2] . Unlike acetylsalicylic acid (ASA), triflusal inhibits phosphodiesterase, the enzyme responsible for degrading cAMP and cGMP, both of which have antiaggregant effects [3]. Also unlike ASA, the endothelial synthesis of prostacyclin is preserved with triflusal [1]. The authorized posology of triflusal capsules is $600 \mathrm{mg}$ (two capsules) in single daily dose or $900 \mathrm{mg}$ (three capsules) in fractionated daily doses.

In controlled clinical trials in patients with acute myocardial infarction [4] and in patients with ischemic stroke or transient ischemic attack [5,6] triflusal administered at a dose of $600 \mathrm{mg}$ daily has demonstrated an efficacy similar to ASA in the prevention of vascular events but with a lower hemorrhagic risk. These results were confirmed in a metaanalysis [7] . Also, the efficacy and tolerability of triflusal in patients with unstable angina [8], aortocoronary bypass [9], bioprosthetic valve replacement [10] and peripheral arterial disease [11], has been evidenced in controlled clinical trials. The association of triflusal and moderate intensity oral anticoagulation is more effective than standard oral anticoagulation to prevent vascular events in patients with atrial fibrillation [12] . Triflusal is well tolerated in patients with ASA-induced asthma [13].

Gastrointestinal tolerability of triflusal is good. In the Triflusal versus Aspirin in Cerebral Infarction Prevention (TACIP) study [5], performed in 2113 patients that suffered an ischemic stroke or transient ischemic attack in the previous six months, the incidence of gastrointestinal hemorrhage was lower with triflusal than with aspirin $(4.6 \%$ vs $7.6 \%$; $\mathrm{p}=$ $0.005)$ as it was the incidence of peptic ulcer $(0.1 \%$ vs $0.8 \% ; \mathrm{p}=0.021)$. However, the incidence of dyspepsia was higher with triflusal than with aspirin $(27.4 \%$ vs $21.7 \%$; $\mathrm{p}=$ 0.002). The previously mentioned metaanalysis [7] evidenced that gastrointestinal hemorrhage was higher with aspirin than with triflusal (OR: 1.83 ; 95\% CI: 1.35 to 2.48 ) whereas nonhemorrhagic gastrointestinal adverse events were lower with aspirin than with triflusal (OR: $0.84 ; 95 \%$ CI. 0.75 to 0.95$)^{7}$. In case-control studies [14,15] triflusal has not been associated with a significant risk of gastrointestinal hemorrhage. 
A new oral $600 \mathrm{mg}(10 \mathrm{ml})$ oral solution form of triflusal demonstrated bioequivalence with triflusal $600 \mathrm{mg}$ capsules [16] and in 2006 the oral solution form of triflusal was authorized in Spain.

The primary aim of this study is to compare the gastrointestinal safety of triflusal oral solution with triflusal capsules in healthy volunteers by means of upper endoscopy evaluation. As secondary objectives the gastrointestinal safety of triflusal oral solution and triflusal capsules were compared with placebo in a wide sample of healthy volunteers.

\section{Subjects and Methods}

\section{Subjects}

Sixty healthy subjects (31 men and 29 women; mean age, 25.8 years; range, 20-42 years) participated in the study. Before entering the study, all subjects were required to provide a complete medical history and undergo a physical examination, electrocardiogram (ECG) and clinical laboratory tests. Subjects were excluded from the study if they met some of the following criteria: history of gastrointestinal disease or current gastrointestinal symptoms; abnormal results concerning vital signs (systolic and diastolic blood pressure, heart rate and body temperature) or ECG; being smoker; alcohol or drug abuse in the previous month or positive urine test for ethanol, cannabis, cocaine, amphetamines, benzodiacepines or opiates; antecedent of hypersensitivity to drugs; consumption of stimulant beverages (more of five coffees, teas or cola beverages at day) in the previous week to the endoscopic examination; intake of any other medication (including over the counter and herbal medicines) in the two previous weeks; seropositivity for hepatitis $\mathrm{B}$ or $\mathrm{C}$ viruses or HIV; positive test for Helicobacter pylori; history of cardiovascular, respiratory, renal, hepatic, endocrine, hematologic or neurological disease or other chronic diseases, surgical intervention in the previous six months, pregnancy or women not using an effective contraceptive method, participation in other clinical trial during the previous three months, being blood donors in the previous four weeks. Moreover, subjects were excluded if they had an abnormal findings on base line endoscopy (endoscopic score $>1$, see below). 


\section{Study Design}

The study was conducted using a randomized, active and placebo controlled, parallel-group design, with a blind evaluator.

In the previous three weeks the evaluation of the inclusion and the exclusion criteria was carried-out. It included anamnesis, physical exam, ECG, blood analysis (haematology, biochemistry and serologies for hepatitis $\mathrm{B}$ and $\mathrm{C}$ viruses, and for $\mathrm{HIV}$ ), a ${ }^{13} \mathrm{C}$-urea breath test for Helicobacter pylori (UB Test. Otsuka Pharmaceutical, S.A.), urine tests for abuse drugs, and pregnancy test in women. During the 24 hours previous to treatment an endoscopic examination to rule-out previous pathology was performed.

Subjects were randomly assigned, in a $2.5: 2.5: 1$ ratio, into three groups that received one bottle of triflusal oral solution (600 mg) daily, two triflusal capsules (600 mg) once daily, and two placebo capsules once daily, respectively. Randomization was performed from a computer-generated balanced list based on the above-mentioned distribution. The study medications were administered daily in the Clinical Pharmacology Department of the Hospital de la Santa Creu i Sant Pau (Barcelona) during seven consecutive days. The first six days being taken at 8 a.m. and the last day (day seven) at 10 a.m. Both capsules and oral solution were taken with $220 \mathrm{ml}$ of water.

Before study commencement all participants gave informed written consent, and approval was obtained from the Ethical Committee of the Hospital de la Santa Creu i Sant Pau (Barcelona) as well as from the Spanish Health Authorithies.

\section{Assessment}

Endoscopies were performed after 4-8 hours of the last dose of study drugs, using an Olympus or Pentax video gastroscope ( Olympus; Europe, Hamburg Germany). All subjects received sedation with midazolam ( dose $2 \mathrm{mg}$ ) or propofol. (doses ranged between 70 to 260 $\mathrm{mg}$ ) immediately before endoscopic intubation. The esophagus, the entire stomach and duodenum were systematically examined in a proximal to distal manner. Each endoscopic procedure was documented by photographies. Hemorrhagic and erosive mucosal lesions were graded using the standard score scale devised by Lanza [17] and modified by the 
Gastroenterology Department of the Hospital de la Santa Creu i Sant Pau (Barcelona). Scores were assigned as follows: normal, 0 points; erythema, 1 point; 1-3 erosions or petechiae, 2 points; 4-5 erosions or petechiae, 3 points; 6-10 erosions or petechiae, 4 points; > 10 erosions or petechiae, 5 points; ulcer: 6 points. Separate endoscopic injury scores were assessed (assigned) for the esophagus, stomach and duodenum until second portion. The median scores for each of the three treatment groups were calculated. Gastroscopies were documented with photographs. Two endoscopists (SS and J Ba) were involved in the study. In each volunteer basal and final endoscopies were performed by the same endoscopist who was blinded to the assigned treatment.

Subjects were provided of a diary card in order to register the following symptoms: heatburn, dysphagia, regurgitation, abdominal bloating, nausea and epigastric pain. Intensity of these symptoms was scored as follows: absence, 0 ; mild, 1; moderate, 2; severe, 3 . These symptoms were also assessed by means of a visual analogic scale (VAS) of $100 \mathrm{~mm}$ in which 0 was absence of symptoms and 100 the poor possible symptom. Patients marked in the VAS from the day one to the day seven, after medication intake.

Blood analysis (haemathology and biochemistry) and ECG were repeated at 24-72 hours of last dose of study drugs.

All reported adverse events and abnormal laboratory findings were recorded and tabulated by treatment group. Causality relationship was defined according to the World Health Organization criteria [18].

\section{Statistical analysis}

Based on the results of Fiorucci et al [19], a sample of 50 subjects (25 in each one of the active treatment arms) would be required to achieve a $80 \%$ power to detect a difference of 1.65 points between triflusal oral solution and triflusal capsules in the modified Lanza scale. Besides, a sample of 10 subjects in the placebo group was also included for comparison with the active drugs.

Main and secondary variables were analysed by means a Kruskall-Wallis test comparing the three study treatments. When differences were found, comparisons between groups were 
analysed by means a Mann-Whitney test. All analysis were performed with a two sided significance level of 0.05 .

\section{Results}

One hundred and fifteen subjects participed in the screening visit. Forty four volunteers failed to meet selection criteria (28 of them because Helicobacter pylori was present) and were excluded from the study. The rest of 71 subjects had an endoscopy screening with normal results at base line. From these, 10 volunteers were considered as reserves and 61 (31 men) were included in the study. One subject dropped-out due to lack of compliance with the protocol and was not replaced. Sixty volunteers completed the study. Twenty five received triflusal capsules, 25 received triflusal solution and 10 volunteers received placebo. Demographic characteristics are shown in Table 1.

All endoscopies at baseline were considered normal in accordance with the inclusion and exclusion criteria and in any case the endoscopic score was $>1$. When we used the modified Lanza scale, the median injury score at base line was 0 for the three treatment groups, both globally and separately in the stomach, esophagus and duodenum (Table 2). No differences were found between groups. After treatment, median global scores in the placebo, triflusal solution and triflusal capsules groups were, respectively: 0,1 , and 3 ( $p=0.008$ between three treatment groups, Kruskall-Wallis test; $\mathrm{p}=0.003$ for comparison between placebo and triflusal capsules, Mann-Whitney test; and $\mathrm{p}=0.042$ for comparison between triflusal solution and triflusal capsules, Mann-Whitney test). There were no significant differences between triflusal solution and placebo ( $\mathrm{p}=0.212$, Mann-Whitney test). When considered separately, median scores for esophagus or duodenum were 0 in the three treatment groups, whereas in the stomach median scores for placebo, triflusal solution and triflusal capsules were, respectively, 0,0 and $3(p=0.004$ between three treatment groups, Kruskall-Wallis test; $p=0.003$ for comparison between placebo and triflusal capsules, Mann-Whitney test; and $\mathrm{p}=0.022$ for comparison between triflusal solution and triflusal capsules, Mann-Whitney test). No significant differences were found between triflusal solution and placebo. Endoscopic scores after treatment are shown in Table 3. An example of gastroduodenal endoscopies for each treatment is shown in Figure 1. 
Medians for symptoms in VAS and in the diary cards for placebo, triflusal solution and triflusal capsules were 0 in all treatment days. Thus, no differences were detected concerning these variables.

Adverse events were reported in two, nine and seven volunteers in the placebo, triflusal solution and triflusal capsules groups, respectively (Table 4). All adverse events were mild or moderate in intensity. None was serious and all subjects recovered.

\section{Discussion}

We conducted a proof of concept endoscopic and well powered study to compare the gastrointestinal safety of triflusal oral solution with triflusal capsules in healthy volunteers. As secondary objectives the gastrointestinal safety of triflusal oral solution and triflusal capsules were compared with placebo. Subjects enrolled in this study were well matched at baseline with a median injury score of 0 for the three groups of treatment. The median global score in the triflusal capsules group after seven days of treatment increased to 3, compared with an increase to 1 in subjects receiving triflusal solution and with an unchanged score of 0 in subjects receiving placebo. Therefore, our data provide convincing evidence that triflusal solution induce less visible changes in gastroduodenal mucosa than triflusal capsules in subjects without previous gastroduodenal disease. A possible explanation for these findings is that when triflusal is administered in a solid form (capsules) the disgregation of the drug into the stomach can not be uniform, and local concentrations can be particularly high. In addition, the intrinsic acidity of triflusal is high, with a pKa value of 3.0. However, when triflusal solution is administered an homogeneous distribution along the gastric mucose is guaranteed, as well as a faster absorption [16] and, more important, a solution containing the sodium salt of triflusal (as is the case), with a pH between 6 and 7, does not produce the local effects caused by the strong acidity of the solid form (not sodium salt). In a recently published study [20], performed in 609 patients undergoing chronic antiplatelet therapy who presented gastrointestinal disorders attributed to this therapy, mainly with aspirin, the change of the initial antiplatelet therapy for triflusal solution improved treatment tolerability and quality of life of patients. 
Gastrointestinal toxicity of antiplatelet agents such as aspirin and clopidogrel are well known. Even when administered at low doses, aspirin can cause serious gastrointestinal bleeding [21] and the most frequently reported adverse events in both aspirin and clopidogrel groups in the CAPRIE [22] study were gastrointestinal events, although the incidence was lower with clopidogrel. In an attempt to decrease the incidence of serious gastrointestinal side effects associated to aspirin and clopidogrel, proton pump inhibitors are frequently associated to these antiplatelet drugs and, in this sense, the American College of Cardiology/American Heart Association Guidelines in Unstable Angina/Non-ST Elevation Myocardial Infarction [23] recommends than in patients with a history of gastrointestinal bleeding, when aspirin or clopidogrel are administered alone or in combination, drugs to minimize the risk of recurrent gastrointestinal bleeding (e.g., proton pump inhibitors) should be prescribed concomitantly (Class I, Level of Evidence: B). A report of the American College of Cardiology Foundation/American College of Gastroenterology/American College of Cardiology recommends the administration of proton pump inhibitors in patients receiving antiplatelet therapy if gastrointestinal risk factors are present [24]. Recently there is emerging evidence that concomitant administration of proton pump inhibitors diminishes the antiplatelet effect [25] and the clinical efficacy of clopidogrel [26]. For the above mentioned reasons it is convenient to dispose of alternative antiplatelet agents with a good gastrointestinal safety profile such as triflusal.

An antiplatelet drug in oral solution form could be useful to administer through a nasogastric tube as can be the case of patients with ischemic stroke [27]. In this case an antiplatelet drug in form of oral solution could be of interest. On the one hand it avoids the process of trituration of a solid antiplatelet drug, which is an alteration of the original pharmaceutical form, and on the other hand, it spares time to the patient's careers. Moreover, an oral solution can be also useful to be administered to patients with dysphagia to solids for any reason but needing treatment with antiplatelet drugs. In this sense, it is known that about $50 \%$ of institutionalized elderly people has swallowing disorders [28].

Our study has some limitations that should be commented. Firstly, it should be taken into account that changes in gastroduodenal mucose in this kind of studies are not necessarily good predictors of major upper gastrointestinal complications. In this sense, it should me mentioned that results from several endoscopic studies carried out in healthy volunteers supported the hypothesis that enteric-coated aspirin caused less gastric erosion and microbleeding than 
regular formulations [29-31] but no clinical benefits in terms of reduction of gastrointestinal bleeding or ulceration with enteric coating have, therefore, been successfully demonstrated, although the endoscopic studies show that potentially these benefits could exist [32]. Secondly, the sample size was calculated from results of a previously published study [19] whereas the assessment of hemorrhagic and erosive mucosal lesions were grated using the standard score scale devised by Lanza [17] and modified by the Gastroenterology Department of the Hospital de la Santa Creu i Sant Pau (Barcelona). It is not the most desirable from a methodological point of view, but endoscopists participating in the study preferred the scale that they used daily to assess endoscopic results. In third place, the novel galenic presentation of triflusal improved the topical gastroduodenal toxicity but if the lower endoscopically apparent mucosal damage of triflusal solution versus triflusal capsules signifies less major upper gastrointestinal complications remains to be elucidated.

Global tolerability of both triflusal solution and triflusal capsules was good, with no serious adverse events reported.

In conclusion, in subjects without previous gastroduodenal disease, triflusal solution induced less endoscopically apparent mucosal damage than triflusal capsules and did not induce more damage than placebo. Further studies will be required to confirm the long-term safety of triflusal solution in patients.

\section{Acknowledgements}

The authors thank J. Uriach y Compañía, S.A. (Palau-solità I Plegamans, Barcelona, Spain) for financial support to this study, and to Montserrat Puntes, Joan Martínez and Salvador Rico for their assistance during data collection. This study was partially supported by the National Scientific Research Program of the Spanish Ministry of Science and Technology. 


\section{Conflict of interest}

Iñaki Izquierdo, Javier Borja and Iris Blanch are employees of J. Uriach y Compañía, S.A.

Esther Donado was an employee of J. Uriach y Compañía, S.A. when the study was performed. Manel Barbanoj has been external advisor of J. Uriach y Compañía, S.A. 


\section{References}

1.Cruz-Fernández J M (2003) Antiplatelet drugs in the treatment of acute coronary syndromes: Focus on cyclooxigenase inhibitors. Eur Heart J 3 (Suppl I): 123-130

2.Murdoch D, Plosker G L (2006) Triflusal: a review of its use in cerebral infarction and myocardial infarction, and as thromboprohylaxis in atrial fibrillation. Drugs 66: 671-692

3.García-Rafanell J, Ramis J, Gómez L, Forn J (1986) Effect of triflusal and other salicylic acid derivatives on cyclic AMP levels in rat platelets. Arch Int Pharmacodyn Ther 284: 155165

4.Cruz-Fernández JM, López-Bescos L, García-Dorado D, López García-Aranda V, Cabadés A, Martín-Jadraque L, et al (2000) Randomized comparative trial of Triflusal and aspirin following acute myocardial infarction. Eur Heart J 21:457-465

5.Matias-Guiu J, Ferro JM, Álvarez-Sabin J, Torres F, Dolores Jiménez M, Lago A, et al (2003) Comparison of Triflusal and aspirin for prevention of vascular events in patients after cerebral infarction: the TACIP Study: a randomized, double-blind, multicenter trial. Stroke. $34: 840-848$

6.Culebras A, Rotta-Escalante R, Vila J, Domínguez R, Abiusi G, Famulari A, et al (2004) Triflusal vs aspirin for prevention of cerebral infarction. Neurology 2004; 62: 1073-1080

7.Costa J, Ferro JM, Matias-Guiu J, Alvarez-Sabín J, Torres F (2005) Triflusal for preventing serious vascular events in people at high risk. Cochrane Database Syst Rev 3: CD004296

8.Plaza L, López-Bescós L, Martín-Jadraque L, Alegría E, Cruz-Fernández J M, Velasco J, et al (1993) Protective effect of triflusal against acute myocardial infarction in patients with instable angina: results of a Spanish multicenter trial. Cardiology 82: 388-398 
9.Guiteras P, Altimiras J, Arís A, Augé J Mª , Bassons T, Bonal J, et al (1989) Prevention of aortocoronary vein-graft attrition with low-dose aspirin and triflusal, both associated with dipyridamole: a randomized, double-blind, placebo-controlled trial. Eur Heart J 10: 159-167

10.Aramendi J I, Mestres C A, Martínez-León J, Campos V, Muñoz G, Navas C (2005) Triflusal versus oral anticoagulation for primary prevention of thromboembolism after bioprosthetic valve replacement (trac): prospective, randomized, co-operative trial. Eur $\mathbf{J}$ Cardio-Thoracic Surg 27: 854-860

11.Auteri A, Angaroni A, Borgatti E, Catalano M, De Vizzi G B, Forconi S, et al (1995) Triflusal in the treatment of patients with chronic peripheral arteriopathy: multicentre doubleblind clinical study vs placebo. Int J Clin Pharm Res 15: 57-63

12.Pérez-Gómez F, Alegría E, Berjón J, Iriarte J A, Zumalde J, Salvador A, et al (2004) Comparative effects of antiplatelet, anticoagulant, or combined therapy in patients with valvular and nonvalvular atrial fibrillation. J Am Coll Cardiol 44: 1557-1566

13. Fraj J, Valero A, Vives R, Pérez I, Borja J, Izquierdo, et al (2008) Safety of triflusal (antiplatelet drug) in patients with aspirin-exacerbated respiratory diseases. Allergy 63: 112115

14.Lanas A, Serrano P, Bajador E, Fuentes J, Sáinz R (2003) Risk of upper gastrointestinal bleeding associated with non-aspirin cardiovascular drugs, analgesics and nonsteroidal antiinflammatory drugs. Eur J Gastroenterol Hepatol 15: 173-178

15.Ibáñez L, Vidal X, Vendrell L, Moretti U, Laporte J R (2006) Upper gastrointestinal bleeding associated with antiplatelet drugs. Aliment Pharmacol Ther 23: 235-242

16.Izquierdo I, Borja J, Rovira R, Pelagio P, Torres F, Cebrecos J, et al (2010) Comparative bioavailability study of triflusal oral solution vs. triflusal capsules in healthy subjects. Arzneimittelforschung 60:36-41 
17.Lanza F L, Roger G L, Nelson R S (1980) Endoscopic evaluation of the effects of aspirin, buffered aspirin, and enteric-coated aspirin on gastric and duodenal mucusa. N Engl $\mathbf{J}$ Med 303: $136-138$

18.Meyboom R H B, Hekster Y A, Egberts A C G, Gribnau F W J, Edwards I R (1997) Causal or casual?. The role of causality assessment in pharmacovigilance. Drug Saf 17: 374-389

19.Fiorucci S, Santucci L, Gresele P, Faccino R M, Del Soldato P, Morelli A (2003) Gastrointestinal safety of NO-aspirin (NCX-4016) in healthy human volunteers: A proof of concept endoscopic study. Gastroenterology 2003; 124: 600-607

20.Riambau-Alonso V, Fernández S, Lara M, Caballero M D, Rubio E, Martín A (2009) Estudio epidemiológico observacional para evaluar el manejo de los trastornos gastrointestinales en el paciente con tratamiento antiagregante. Angiología 61: 185-194

21.Patrono C, Baigent C, Hirsh J, Roth G (2008) Antiplatelet drugs. American College of Chest Physicians Evidence-Based Clinical Practice Guidelines ( $8^{\text {th }}$ edition). Chest 133: 199S$233 \mathrm{~S}$

22.CAPRIE Steering Committee (1996) A randomised, blinded, trial of clopiodgrel versus aspirin in patients at risk of ischaemic events (CAPRIE). Lancet 348: 1329-1339

23.Anderson J L, Adams C D, Antman E M, Bridges Ch R, Califf R M, Casey D E, et al (2007) ACC/AHA 2007 Guidelines for the Management of Patients With Unstable Angina/Non ST-Elevation Myocardial Infarction. A Report of the American College of Cardiology/American Heart Association Task Force on Practice Guidelines (Writing Committee to Revise the 2002 Guidelines for the Management of Patients With Unstable Angina/Non ST-Elevation Myocardial Infarction). Circulation 116: e148-e304

24.Bhatt D L, Scheiman J, Abraham N S, Antman E M, Chan F K L, Furberg C D (2008) ACCF/ACG/AHA 2008 Expert Consensus Document on Reducing the Gastrointestinal Risks of Antiplatelet Therapy and NSAID Use. A Report of the American College of Cardiology Foundation Task Force on Clinical Expert Consensus Documents. Circulation 118: 1894-1909 
25.Gilard M, Arnaud B, Le Gal G, Abgrall J F, Boschat J (2006) Influence of omeprazol on the antiplatelet action of clopidogrel associated to aspirin. J Thromb Haemost 4: 2508-2509

26.Ho P M, Maddox T M, Wang L, Fihn S D, Jesse R L, Peterson E D, et al. Risk of adverse outcomes associated with concomitant use of clopidogrel and proton pump inhibibitors following acute coronary syndrome. JAMA 2009; 301: 937-944.

27. Adams H P Jr, del Zoppo G, Alberts M J, Bhatt D L, Brass L, Furlan A, et al. Guidelines for the early management of adults with ischemic stroke. Stroke 2007; 38: 1655-1711.

28. Finiels H, Struble D, Jaquot J M. Les troubles de la déglutition du sujet âgé. Presse Med 2001 ; 30: 1623-1634.

29. Hotfiezer J W, Silvoso G R, Burks M, Ivey K J. Comparison of the effects of regular and enteric-coated aspirin on gastroduodenal mucosa on man. Lancet 1980; 2: 609-612.

30. Lanza F L, Royer G L Jr, Nelson R S. Endoscopic evaluation of the effects of aspirin, buffered aspirin, and enteric-coated aspirin on gastric and duodenal mucosa. $\mathrm{N}$ engl $\mathbf{J}$ Med 1980; 303: 136-138.

31. Hawthorne A B, Mahida Y R, Cole A T, Hawkey C J. Aspirin-induced gastric mucosa damage: prevention by enteric-coating and relation to prostaglandin synthesis. $\mathrm{Br} \mathrm{J}$ Clin Pharmacol 1991; 32: 77-83.

32. Walker J, Robinson J, Stewart J, Jacob S. Does enteric-coated aspirin result in a lower incidence of gastrointestinal complications compared to normal aspirin?. Interact CardioVasc Thorac Surg 2007; 6: 519-522.

Table 1. Demographic characteristics of healthy volunteers $(N=60)$ 


\begin{tabular}{|lcc|}
\hline Characteristic & Mean (SD) & Range \\
\hline Age $(\mathrm{y})$ & $25.85(4.25)$ & $20.00-42.00$ \\
Weight $(\mathrm{kg})$ & $67.94(10.32)$ & $50.00-85.50$ \\
Height $(\mathrm{cm})$ & $171.87(9.01)$ & $151.00-189.00$ \\
$\begin{array}{l}\text { Body mass index } \\
\left.\text { Quetelet's index }\left[\mathrm{kg} / \text { height }^{2}\right]\right)\end{array}$ & $22.91(2.00)$ & $19.00-22.00$ \\
\hline
\end{tabular}

Table 2. Median (minimum, maximum) basal endoscopic scores 


\begin{tabular}{|lcccc|}
\hline Treatment & Esophagus & Stomach & Duodenum & Global \\
\hline Placebo & & & & \\
& 0 & 0 & 0 & 0 \\
Triflusal solution & 0 & $(0,1)$ & $(0,0)$ & $(0,1)$ \\
& $(0,0)$ & 0 & 0 & 0 \\
Triflusal capsules & 0 & $(0,1)$ & $(0,0)$ & $(0,1)$ \\
& $(0,1)$ & 0 & 0 & 0 \\
No differences were found between groups. & $(0,1)$ & $(0,0)$ & $(0,1)$ \\
\hline
\end{tabular}

Table 3. Median (minimum, maximum) endoscopic scores after treatments 


\begin{tabular}{|lcccc|}
\hline Treatment & Esophagus & Stomach & Duodenum & Global \\
\hline Placebo & & & & \\
& 0 & 0 & 0 & 0 \\
Triflusal solution & 0 & $(0,2)$ & $(0,0)$ & $(0,2)$ \\
& $(0,0)$ & 0 & 0 & 1 \\
Triflusal capsules & 0 & $(0,5)$ & $(0,5)$ & $(0,6)$ \\
& $(0,2)$ & $(0,5)$ & 0 & $3 * * * *$ \\
& & & & $(0,3)$ \\
$* \mathrm{p}<0.05$ vs triflusal solución & & & \\
$* * \mathrm{p}<0.01$ vs placebo & & & & \\
\hline
\end{tabular}

Table 4. Adverse events reported during the study 


\begin{tabular}{|c|c|c|c|c|c|c|c|c|}
\hline \multicolumn{3}{|c|}{ Placebo } & \multicolumn{3}{|c|}{ solution } & \multicolumn{3}{|c|}{ capsules } \\
\hline $\begin{array}{l}\text { Subject } \\
\text { number }\end{array}$ & $\begin{array}{l}\text { Adverse } \\
\text { event }\end{array}$ & $\begin{array}{l}\text { Causality } \\
\text { relationship }\end{array}$ & $\begin{array}{l}\text { Subject } \\
\text { number }\end{array}$ & $\begin{array}{l}\mathrm{t} \text { Adverse } \\
\mathrm{r} \text { event }\end{array}$ & $\begin{array}{l}\text { Causality } \\
\text { relationship }\end{array}$ & $\begin{array}{l}\text { Subject } \\
\text { number }\end{array}$ & $\begin{array}{c}\text { Adverse } \\
\text { event }\end{array}$ & $\begin{array}{l}\text { Causality } \\
\text { relationship }\end{array}$ \\
\hline 01 & Headache & Possible & 06 & $\begin{array}{c}\text { Diarrhoea } \\
\text { Dysmenorrhea }\end{array}$ & $\begin{array}{l}\text { Possible } \\
\text { Conditional/NC }\end{array}$ & 22 & Dizziness & Possible \\
\hline \multirow[t]{8}{*}{56} & Vomiting & Possible & 11 & Anorexia & Possible & 27 & Headache & Possible \\
\hline & & & 13 & Constipation & Possible & 30 & Pain & Possible \\
\hline & & & 14 & $\begin{array}{c}\text { Drowsiness } \\
\text { Headache }\end{array}$ & $\begin{array}{l}\text { Conditional/NC } \\
\text { Possible }\end{array}$ & ${ }^{40} \mathrm{D}$ & $\begin{array}{l}\text { Headache } \\
\text { ysmenorrhea } \\
\text { Cold }\end{array}$ & $\begin{array}{l}\text { Possible } \\
\text { Conditional/NC } \\
\text { Conditional/NC }\end{array}$ \\
\hline & & & 20 & Headache & Possible & & Cough & Conditinal/NC \\
\hline & & & 35 & $\begin{array}{l}\text { Diarrhoea } \\
\text { Anxiety } \\
\text { Hyperactivity }\end{array}$ & $\begin{array}{l}\text { Possible } \\
\text { Possible } \\
\text { y Unlikely }\end{array}$ & 48 & Headache & Possible \\
\hline & & & 39 & Headache & Possible & 49 & Headache & Possible \\
\hline & & & 59 & Neck crik & Unlikely & 58 & Headache & Possible \\
\hline & & & 61 & Headache & Possible & & & \\
\hline
\end{tabular}


Figure 1. Photography samples obtained during endoscopic in each treatment group ; A) normal mucosa in stomach fundus after treatment with placebo ; B) normal mucosa in stomach after treatment with triflusal solution; and C) mild erosive mucosal lesions, grade ? after treatment with triflusal capsules.

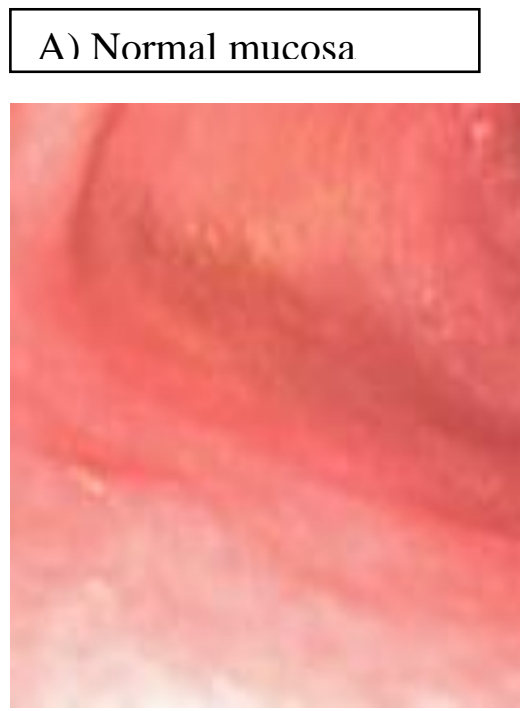

B) Normal mucosa

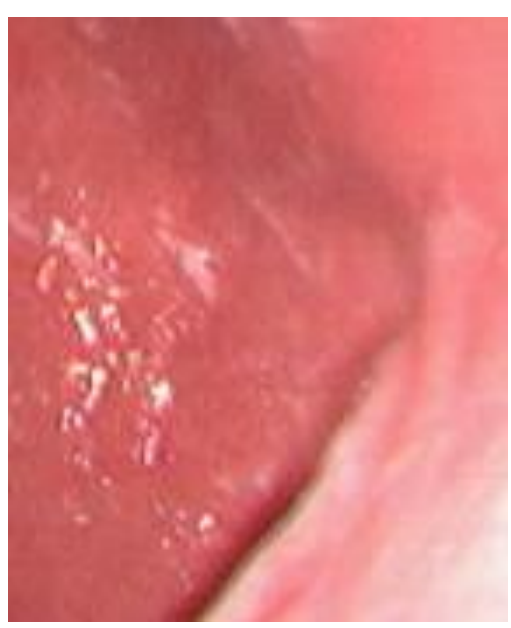

C.) Erosive mucosal lesions

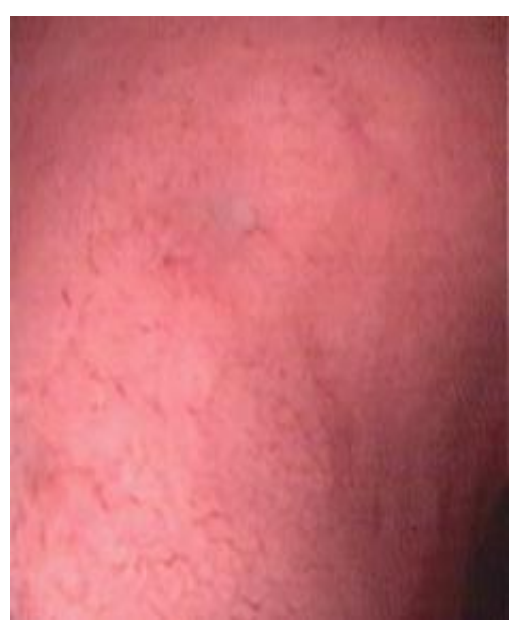

